\title{
HUBUNGAN MEMORABLE CULINARY TOURISM EXPERIENCES DAN MINAT BERKUNJUNG KEMBALI WISATAWAN DI WARUNG KOPI KLOTOK YOGYAKARTA
}

\author{
Intan Widyaningrum Puji Rahayu \\ Program Studi Pariwisata, Fakultas Ilmu Budaya, Universitas Gadjah Mada \\ Email: intanwpr@gmail.com \\ Mohamad Yusuf \\ Program Studi Pariwisata, Fakultas Ilmu Budaya, Universitas Gadjah Mada \\ Email:myusuf@ugm.ac.id
}

\begin{abstract}
Several studies have confirmed that experience is the main goal of the tourism industry and as a significant impression for the tourist. However, there has been few studies investigating the memorable tourism experience (MTE) concept in culinary tourism, and more specifically in traditional culinary tourism, which is called the Memorable Culinary Tourism Experience (MCTE). This research aims to investigate the application of MCTE in traditional culinary tourism of Warung Kopi Klotok, and to discover the correlation between MCTE and the tourist revisit intention. Five aspects of MCTE were applied, namely local culture, decore, service quality, social interaction, and novelty. There were 267 respondents involved in this research coming from various areas in Indonesia. Two steps of data analysis were performed. We conducted a descriptive analysis to investigate level of agreement of tourist toward MTCE variables. In addition, we conducted a correlation analysis to investigate the extend of which MCTE variables are correlated with tourist revisit intention. This study shows that local culture has the highest level of agreement among the tourists, followed by social interaction, décor, service quality and novelty. Social interaction has the higest and positive correlation with tourist revisit intention, followed by décor. Interestingly, local culture has the second lowest and positive correlation with revisit intention after novelty variable.
\end{abstract}

Keywords: culinary tourism, memorable culinary tourism experience, revisit intention, Warung Kopi Klotok Pakem, Yogyakarta 


\section{Pendahuluan}

Tourism experiences atau pengalaman dalam berwisata merupakan salah satu hal terpenting dari industri pariwisata serta merupakan kesan penting yang didapat oleh seseorang saat mengunjungi suatu destinasi wisata (Wu, et al., 2017:326). Pengalaman berwisata yang didapatkan menjadi suatu pengalaman yang terkenang, atau disebut dengan Memorable Tourism Experience (MTE) (Kim et al., 2010:13). Kim (et al., 2010:20) menjelaskan bahwa MTE memiliki tujuh unsur yang terbentuk dari tourism experience (pengalaman berwisata), yaitu hedonism (hedonisme), refreshment (penyegaran), novelty (kebaruan), culture (budaya) dan social interaction (interaksi sosial), knowledge (pengetahuan), meaningfulness (kebermaknaan), dan involvement (keterlibatan).

Pengalaman individu dalam pembelian suatu produk/layanan menjadi sumber informasi penting untuk pengambilan keputusan di masa depan (Singh dan Singh, 2019:553). Seseorang akan mengingat pengalaman masa lalu mereka ketika mereka memutuskan untuk melakukan perjalanan dan mencari informasi mengenai pemilihan tempat yang akan dituju.

Keterkaitan antara MTE dan minat berkunjung kembali telah cukup sering diteliti. Huang dan Hsu (2009:31), misalnya, ketika melakukan penelitian terhadap wisatawan Cina, menemukan bahwa salah satu faktor yang memengaruhi minat berkunjung kembali ialah pengalaman masa lalu yang telah didapat. Selanjutnya, Kim (et al., 2012:501) melakukan studi terhadap mahasiswa Amerika di Korea mengenai pengalaman berwisata di Korea, dan dalam studinya tersebut, mereka membuktikan bahwa pengalaman positif yang didapatkan berbanding lurus dengan minat berkunjung kembali. Selain itu, kajian yang dilakukan di Mulu National Park Malaysia menunjukkan bahwa wisatawan yang mendapatkan MTE yang positif dapat meningkatkan minatnya untuk berkunjung kembali (Mahdzar et al., 2015:37). 
Stone (et al., 2017:1123) mencoba mengadaptasi konsep MTE dalam konteks wisata kuliner, yang dikenal sebagai Memorable Culinary Tourism Expereience (MCTE). Stone et al. menekankan bahwa terdapat lima aspek utama dalam MCTE, yaitu: (1) budaya lokal, (2) dekorasi, (3) kualitas pelayanan, (4) interaksi sosial, dan (5) kebaruan. Penelitian ini mencoba mengadaptasi konsep MCTE yang diperkenalkan oleh Stone et al., dan melihat bagaimana pengaruh variable MCTE tersebut terhadap minat berkunjung kembali di objek wisata kuliner tradisional di salah satu objek wisata kuliner tradisional di Yogyakarta.

Kementerian Pariwisata dan Ekonomi Kreatif telah sejak lama menetapkan Yogyakarta sebagai salah satu destinasi wisata kuliner prioritas, khususnya wisata kuliner tradisional ${ }^{1}$. Sebagai salah satu objek wisata kuliner tradisional yang ada di Yogyakarta adalah Warung Kopi Klotok yang mulai dibuka pada tahun 2015 dan saat ini telah menjadi icon wisata kuliner di Yogyakarta². Warung ini bahkan juga menjadi salah satu destinasi wisata kuliner yang sering dicari dalam mesin pencarian daring (Devian, 2018).

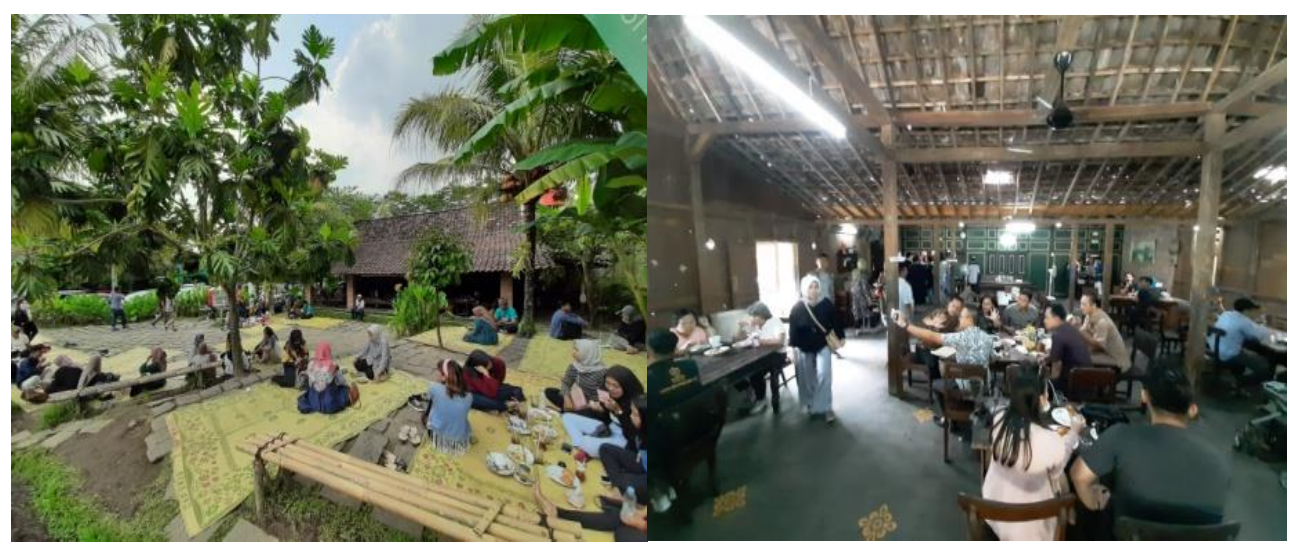

Gambar 1. Suasana di Warung Kopi Klotok

Sumber: Rahayu, 2020

\footnotetext{
${ }^{1}$ News: Maksimalkan Kuliner, Kemenpar CO-Branding 100 Restoran Diaspora. Diakses pada hari Selasa, 5 Mei 2020. (http://www.kemenparekraf.go.id/index.php/post/news-maksimalkan-kuliner-kemenpar-co-branding-100-restoran-diaspora)

2 Wawancara dengan pemilik Warung Kopi Klotok pada 23 Januari 2020 
Warung Kopi Klotok merupakan restoran yang bernuansa kuno dan tradisional, bersuasana pedesaan dengan pemandangan persawahan dan gunung Merapi, serta menyediakan menu masakan rumahan. Selain itu, Warung kopi ini juga menawarkan arsitektur dan ornamen bangunannya dengan nuansa Jawa kuno. Di Warung ini proses pembuatan hidangan dilakukan dengan menggunakan tungku kayu bakar tradisional di dapur yang bergaya lawas dan berada di halaman belakang yang berbatasan dengan lahan perkebunan jagung. Menu yang dihadirkan ialah makanan rumahan yang saat ini sudah mulai sulit untuk ditemui ${ }^{3}$. Warung ini mencoba membangkitkan memori pengunung atas kehidupam masyarakat Jawa kuno, khususnya melalui ornament bangunan, menu makanan dan cara menghidangkan makanan.

Berdasarkan pemaparan di ata, maka penelitian ini akan mencoba menjawab tiga rumusan masalah utama yaitu: pertama, bagaimana karakteristik wisatawan yang berkunjung ke Warung Kopi Klotok? Kedua, bagaimana tingkat persetujuan wisatawan terhadap masing-masing variable Memorable Culinary Tourism Experience (MCTE)? Dan ketiga, bagaimana hubungan antrata MCTE terhadap minat kunjungan kembali wisatawan?

\section{Kerangka Berfikir}

Selanjutnya pada bagian ini akan dipaparkan mengenai hubungan antara pariwisata dengan kuliner, serta pengalaman berwisata kuliner. Beberapa kajian telah menunjukkan bahwa pariwisata merupakan aktivitas yang dapat memberikan pengalaman yang berbeda-beda terhadap setiap individu (Coelho, 2018, Ageeva, \& Poroudi, 2019; Gerdt, et al., 2019; Hallak, et al., 2018), sehingga, pariwisata

\footnotetext{
3"Selalu Ramai Pengunjung, Pemilik Kopi Klotok Berbagi Rahasia Usahanya". Diakses pada Jumat, 30 Agustus 2019. (https://ekonomi.kompas.com/read/2018/10/01/101643426/selalu-ramai-pengunjung-pemilik-kopi-klotok-berbagi-rahasiausahanya?page=all)
} 
menekankan pada aktifitas yang menjual pengalaman (Lee, et al., 2016; Papadimitriou, et al., 2018). Pengalaman yang didapat oleh seseorang akan tertinggal dalam ingatannya, didahului oleh motivasi dan ekspektasi, serta kemudian menghasilkan kepuasan atau ketidakpuasan (Kim et al., 2010:13). Pengalaman yang berkesan pada masa lalu begitu penting dalam industry pariwisata karena memiliki tiga hal penting, yaitu: (1) tingkat motivasi dan keterlibatan akan meningkat saat informasi berasal dari pengalaman individu seseorang, (2) seseorang akan menganggap pengalamannya di masa lalu adalah hal yang kredibel, serta (3) pengalaman yang diingat akan memengaruhi pengambilan keputusan di masa depan (Tan et al., 2016; Tsai, 2015). Di sisi lain, hal itu tidak menutup kemungkinan bahwa setelah adanya aktivitas berkunjung maka destinasi tersebut akan direkomendasikan kepada orang lain (Huang \& Hsu, 2009:31).

Salah satu bentuk wisata yang dapat memberikan pengalaman bagi wisatawan adalah food tourism atau wisata kuliner. Wisata kuliner dipandang sebagai sumber yang berarti bagi kesan dan pengalaman yang dapat ditawarkan terhadap pengunjung (Hjalager \& Richards, 2002:11). Menurut Hjalager \& Richards (2002:11) dan Yusuf (2017), sebagian besar dari kebanyakan pengalaman seseorang saat melakukan perjalanan wisata dihabiskan untuk mengonsumsi makanan dan minuman atau memutuskan apa serta di mana untuk mengonsumsinya.

Pariwisata dan kuliner merupakan hal yang tidak dapat dipisahkan karena makan menjadi kegiatan yang paling penting bagi manusia untuk bertahan hidup (Park, et al., 2019:4). Wisata kuliner merupakan salah satu atraksi wisata untuk menarik pengunjung dengan menghadirkan pengalaman unik serta makanan dan minuman yang mengesankan (Smith \& Costello, 2008:99). Pengalaman wisata kuliner dapat menambah nilai bagi pariwisata dengan menyediakan hubungan 
antarabudaya, lanskap, dan makanan lokal, serta menciptakan 'atmosfer' yang menjadi bagian penting bagi MTE (Hjalager \& Richards, 2002:224).

Wisata kuliner menjadi salah satu bidang yang menarik dan populer dalam industri pariwisata (Baltescu, 2016:107). Wisata kuliner juga merupakan elemen budaya paling signifikan kedua dari daya tarik suatu destinasi (Stone et al., 2017:1130). Selanjutnya, dalam satu dekade terakhir, peran makanan saat berwisata menjadi hal penting (Stone et al., 2017:1121). Menurut Hall \& Sharpless (2003:4) wisata kuliner merupakan salah satu elemen penting yang dapat memengaruhi pengalaman wisatawan. Pengalaman mengesankan yang didapat dari makanan dan minuman meningkatkan kepuasan wisatawan dan positive word of mouth (Stone, 2017:1121). Selain itu, menurut Fernandez \& Cruz (2016:374), jika seseorang mendapatkan pengalaman yang mengesankan maka akan memberikan dampak positif terhadap minat berkunjung kembali dan minat untuk merekomendasikan kepada orang lain.

Pengalaman berwisata kuliner merupakan konsep yang berasal dari berbagai aspek. Dalam hal ini, untuk memberikan pengalaman berwisata kuliner maka hal itu bermula melalui penyajian makanan dengan pengaturan, tempat, waktu, dan tujuan yang berbeda (Peter \& Kauppinen-Räisänen, 2014:4). Selanjutnya, menurut Stone et al., (2017:1124) Memorable Culinary Tourism Experiences (MCTEs) dipengaruhi oleh beberapa aspek, sebagaimana berikut.

\section{1) Local Culture/Budaya Lokal}

Budaya lokal menjadi salah satu aspek yang memengaruhi MTE dan juga menjadi salah satu dimensi yang memengaruhi MCTE. Kim (2014:42) menjelaskan bahwa aspek budaya lokal pada MTE membahas tentang berbagai peluang untuk merasakan gaya hidup lokal, budaya lokal, dan mempelajari sejarahnya. Selanjutnya, pada MCTE, budaya lokal ialah menawarkan kesempatan untuk merasakan hidangan yang dibuat dengan bahan, resep, dan teknik lokal (Stone, 2017:1124). Bagi Kim 
(2014:37), merasakan budaya lokal merupakan faktor motivasi penting untuk bepergian dan dapat membuat perjalanan wisata lebih berkesan. Selain itu, merasakan budaya lokal dapat meningkatkan MTEs secara signifikan. Lin \& Mao (2015:25) mengatakan bahwa merasakan makanan lokal tidak hanya merasakan cita rasanya saja, namun secara tidak langsung juga turut merasakan budayanya.

\section{2) Décor/Dekorasi}

Dekorasi juga menjadi salah satu dimensi yang memengaruhi MCTE, dalam hal ini, dekorasi adalah memadukan hidangan yang disajikan dengan musik, interior, warna, dan bau sehingga menciptakan atmosfer suasana yang sesuai (Stone, 2017:1124). Mengacu pada definisi dekorasi menurut Stone (2017:1124), dimensi ini merupakan gabungan dari beberapa aspek, yaitu arsitektur, fisiografi, dan superstruktur. Mengadaptasi dari definisi asli infrastruktur di suatu destinasi, Kim (2014:38) mengatakan bahwa dimensi infrastruktur ini harus dapat merangsang imajinasi pengunjung dan memfasilitasi kemampuannya untuk menciptakan momentum yang mengesankan saat berkunjung. Suasana dapat menciptakan keterikatan emosional pengunjung sehingga kemungkinan dapat meningkatkan minat berkunjung kembali dan menjadi salah satu kesan pertama ketika mengunjungi restoran. Selain itu, kebersihan juga merupakan salah satu hal yang dapat mendukung suasana yang nyaman bagi pengunjung (Bhuiyan \& Iqrar, 2019:17).

\section{3) Service Quality/Kualitas Pelayanan}

Penelitian ini mendasari kualitas pelayanan oleh sejauh mana staff dapat berperilaku sopan, ramah, dan membantu. Dalam penelitian yang dilakukan oleh Kim (2014:38), dijelaskan bahwa kualitas pelayanan merupakan kemampuan suatu destinasi dalam memberikan pelayanan kepada pengunjungnya dan menunjukkan kinerja pelayanan yang baik agar dapat bersaing dengan destinasi lain. Beberapa 
atribut ketentuan terhadap kualitas pelayanan terdapat dalam pelayanan yang dapat diandalkan, responsif, dan dapat memenuhi permintaan pengunjung (Kim, 2014:38).

4) Social Interaction/Interaksi Sosial

Dalam penelitian ini, interaksi sosial berkaitan dengan pengalaman makanan/minuman yang dapat menumbuhkan interaksi sosial antara pengunjung dengan kelompok perjalanannya. Menurut Kim (2014:36-37) tourism experience diciptakan bersama dengan melibatkan orang lain. Selanjutnya, dalam studinya, Chandralal \& Valenzuela (2013:179) menggabungkan wisatawan untuk terlibat dalam interaksi sosial satu sama lain. Hal tersebut dapat memberikan kontribusi positif bagi pengalaman berwisata. Chandralal \& Valenzuela (2015:303) mengungkapkan bahwa beberapa pengalaman berwisata lebih berkesan bagi seseorang dari pada yang lain karena dinamika sosial di antara teman perjalanan dan wisatawan lain atau dengan penduduk setempat. Dalam penelitian Chandralal et al., (2014:686) diungkapkan bahwa pengalaman wisata yang dibagikan dengan teman dekat dan wisatawan lain cenderung menjadi kenangan indah. Hal tersebut juga dicantumkan wisatawan yang membagikan cerita perjalanannya dalam suatu blog yang digambarkan melakukan interaksi bersama orang lain dan terasa lebih menyenangkan.

\section{5) Novelty/Kebaruan}

Penelitian ini mengacu kebaruan pada sejauh apa suatu hidangan dapat memberikan intensifikasi pengalaman kehidupan sehari-hari dengan menawarkan fitur baru, segar, dan asli. Kim (2014:36) mengemukakan bahwa kebaruan didiskusikan sebagai salah satu komponen penting lainnya dari pengalaman berwisata secara subjektif dan motivasi seorang atau individu untuk melakukan perjalanan. Dalam penelitiannya, Chandralal \& Valenzuela (2013:179) mengonfirmasi bahwa kebaruan yang dirasakan berasal dari pengalaman mengenai sesuatu hal yang baru (salah satunya adalah merasakan makanan yang berbeda) dan itu merupakan 
hal yang dapat memengaruhi MTE. Chandralal \& Valenzuela (2015:302) juga mengatakan bahwa seseorang diasumsikan menganggap bahwa suatu destinasi atau perjalanan berbeda jika ia dapat menikmati pengalaman baru dan unik yang dapat meningkatkan ingatannya mengenai destinasi atau pengalaman tersebut.

Pada penelitian ini kami mengadaptasi kelima dimensi dari Memorable Culinary Tourism Experiences (MCTE) dari penelitian Stone (et al., 2017) sesuai dengan yang telah dijelaskan sebelumnya. MCTE di Warung Kopi Klotok Pakem Yogyakarta tersebut kemudian akan ditinjau hubungannya dengan minat berkunjung kembali yang mengadaptasi dari penelitian yang dilakukan oleh Lin (2012), minat berkunjung kembali dibagi ke dalam dua indikator, yaitu intention to revisit atau minat berkunjung kembali dan intention to recommend atau minat untuk merekomendasikan kepada orang lain. Bagan di bawah ini merupakan penggambaran hubungan ke lima dimensi dari MTCE terhadap minat berkunjung kembali. Berikut ini disampaikan kerangka konseptual yang kami gunakan dalam studi ini.

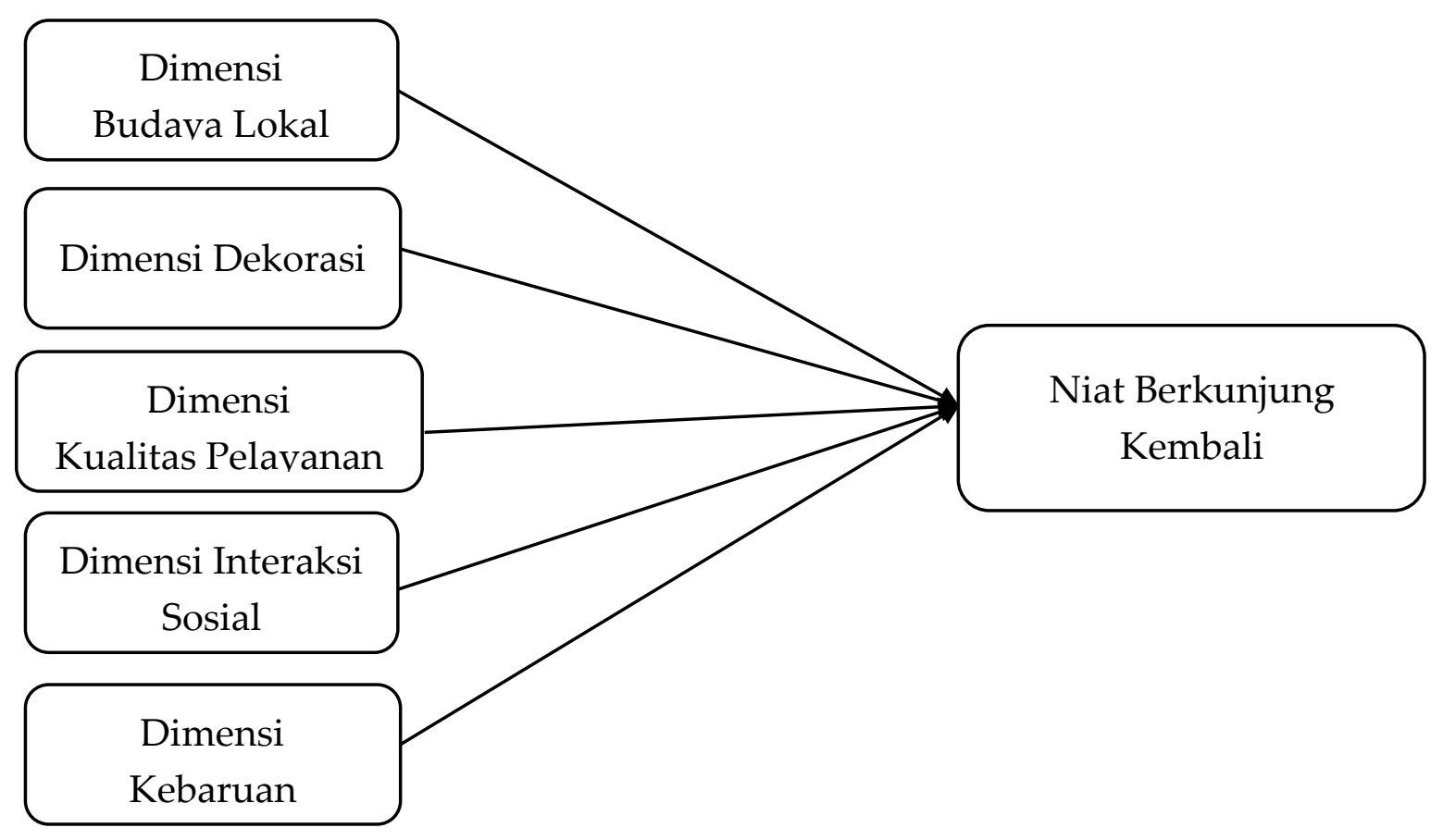

Gambar 2. Kerangka Konseptual 


\section{Metode Penelitian}

\section{Metode Pengumpulan Data}

Penelitian ini menggunakan metode kuantitif, dengan menlihat hubungan antara satu variable dengan variable yang lain. Untuk itu, penelitian ini dilakukan dengan penyebaran kuesioner. Penyebaran kuesioner dilakukan kepada pengunjung di Warung Kopi Klotok pada tanggal 18 - 25 Desember 2018 dengan lama pengisian kuesioner sekitar 10 - 20 menit dan jenis kuesioner tertutup. Empat skala Likert digunakan dalam penelitian ini dengan rincian jawaban tingkat persetujuan sebagai berikut, 1 = sangat tidak setuju, 2 = tidak setuju, 3 = setuju, dan $4=$ sangat setuju.

Kuesioner terdiri dari tiga bagian. Bagian pertama berisikan karakteristik wisatawan. Bagian kedua terdiri dari butir-butir pernyataan terkait indikator Memorable Culinary Tourism Experiences dengan lima dimensi yaitu, budaya lokal (diberi kode LC), dekorasi (D), kualitas pelayanan (SQ), interaksi sosial (SI), dan kebaruan $(\mathrm{N})$. Sementara itu, Bagian ketiga berisi butir-butir pernyataan untuk mengetahui minat wisatawan untuk berkunjung kembali ke Warung Kopi Klotok Pakem (diberi kode R). Populasi pada penelitian ini merupakan seluruh pengunjung di Warung Kopi Klotok Pakem Yogyakarta tanpa membedakan wisatawan dan nonwisatawan. Penyebaran kuesioner pada penelitian ini menggunakan teknik random sampling. Penghitungan sampel pada penelitian ini menggunakan rumus sampel menurut Purba Halady Rao (2008:17)

$$
n=\frac{\mathrm{Z}^{2}}{4 \cdot(\text { Margin of Error })^{2}}
$$

Keterangan:

$\mathrm{n}=$ sampel,

$\mathrm{Z}=$ tingkat kepercayaan/signifikan 
Tingkat kepercayaan/signifikansi yang digunakan adalah 95\% sehingga nilai Z yang dilihat dari tabel distribusi normal adalah sebesar 1,96. Margin of error sebesar $6 \%$, maka penentuan jumlah sampel adalah sebagai berikut:

$$
\begin{gathered}
n=\frac{1,96^{2}}{4 \cdot(0,06)^{2}} \\
=\frac{3,8416}{4 \cdot(0,0036)} \\
=\frac{3,8416}{0,0144} \\
=266,777778=267 \text { responden }
\end{gathered}
$$

\section{Metode Analisis Data}

Setelah melalui uji validitas dan realibilitas, terdapat 27 indikator/item pernyataan yang diujikan kepada pengunjung. Analisis data statistik terkait karakteristik dijelaskan secara deskriptif. Selanjutnya, respon pengunjung terkait masing-masing dimensi dianalisis sesuai dengan tingkat persetujuan responden terhadap masing-masing item pernyataan dari seluruh dimensi yang didapatkan dari hasil perkalian antara frekuensi (f) dengan skor jawaban tingkat persetujuan yang sesuai bobot nilai skala Likert, kemudian akan menunjukan nilai jumlah perkalian (skor) dalam setiap item jawaban. Hasil yang didapatkan dari skor item pernyataan ataupun skor setiap dimensi akan ditinjau sesuai dengan skala kriteria yang ditentukan, yaitu melalui rumus berikut ini (Umar, 1998:225).

$$
R S=\frac{n(m-1)}{m}
$$

Keterangan:

$\mathrm{n}=$ jumlah sampel

$\mathrm{m}=$ jumlah alternatif setiap jawaban tingkat persetujuan 
Berikut ini penghitungan rentang skala dengan jumlah sampel (n) sebanyak 267 responden dan menggunakan four-point scale Skala Likert (m) :

$$
\begin{aligned}
R S & =\frac{267(4-1)}{4} \\
& =\frac{801}{4} \\
& =200,25
\end{aligned}
$$

Dalam menentukan acuan analisis deskriptif terhadap penelitian ini, kami mengacu pada tabel interpretasi skala penilaian tingkat persetujuan responden yang penentuan rentang/interval skalanya sesuai dengan rumus di atas. Berikut tabel interpretasi interval kriteria tingkat persetujuan dalam penelitian ini.

Tabel 1. Interval Skala Penilaian Tingkat Persetujuan

\begin{tabular}{|l|l|}
\hline Skala Penilaian & Tingkat Persetujuan \\
\hline $267-467,25$ & Sangat Rendah \\
\hline $467,26-667,50$ & Rendah \\
\hline $667,51-867,75$ & Tinggi \\
\hline $867,76-1068$ & Sangat Tinggi \\
\hline
\end{tabular}

Model analisis korelasi digunakan dalam penelitian ini untuk menentukan ada tidaknya hubungan antara Memorable Culinary Tourism Experiences (MCTEs) terhadap minat berkunjung kembali di Warung Kopi Klotok Pakem Yogyakarta. Menurut Dwyer et. al. (2012:19), model analisis korelasi menguji kekuatan hubungan antara dua variabel dengan menghitung koefisien korelasi. Pada penelitian ini menggunakan uji korelasi Spearman yang akan menghasilkan koefisien korelasi (rs) 
dan tingkat signifikansi (sig.). Nilai koefisien korelasi - sebagaimana juga taraf signifikansi - digunakan sebagai pedoman untuk menentukan suatu hipotesis dapat diterima atau ditolak dalam suatu penelitian (Bungin, 2005:194). Nilai koefisien korelasi menggambarkan sejauh mana hubungan antara dua variabel (De Vaus, 2002:263). Pada penelitian ini nilai koefisien korelasi setiap dimensi digunakan untuk mengetahui hubungan antar dimensi terhadap minat berkunjung kembali di Warung Kopi Klotok Pakem Yogyakarta.

\section{Hasil dan Pembahasan}

Selanjutnya akan dipaparkan hasil penelitian. Bagian ini dibagi menjadi tiga pembahasan, pertama, karakteristik pengunjung Kopi Klotok, kedua, tingkat persetujuan respondent terhadap variable MCTE, dan ketiga, pengaruh MCTE terhadap minat kunjungan kembali wisatawan.

Tabel 2. Karakteristik Pengunjung Warung Kopi Klotok Pakem Yogyakarta

\begin{tabular}{llll}
\hline Variabel & Kategori & Jumlah & $\mathbf{\%}$ \\
\hline \multirow{2}{*}{ Jenis Kelamin } & Laki-laki & 137 & 51,3 \\
& Perempuan & 130 & 48,7 \\
\hline \multirow{3}{*}{ Umur } & $18-25$ tahun & 219 & 82 \\
& $26-35$ tahun & 39 & 14,6 \\
& $36-45$ tahun & 8 & 3 \\
& $\geq 45$ tahun & 1 & 0,4 \\
\hline \multirow{3}{*}{ Pekerjaan } & Pelajar/Mahasiswa & 174 & 65,2 \\
& PNS/TNI/Polri & 11 & 4,1 \\
& Karyawan & 41 & 15,4 \\
& Wirausaha & 21 & 7,9 \\
& Lain-lain & 20 & 7,5 \\
\hline \multirow{3}{*}{ Pendidikan Terakhir } & SMP & 1 & 0,3 \\
& SMA & 133 & 49,8 \\
& Diploma & 16 & 6 \\
& S1 & 100 & 37,5 \\
& S2/S3 & 17 & 6,4 \\
\hline
\end{tabular}




\begin{tabular}{llll}
\hline & Bali & 2 & 0,7 \\
& Banten & 6 & 2,2 \\
& DKI Jakarta & 30 & 11,2 \\
& Jawa Barat & 20 & 7,5 \\
& Jawa Tengah & 51 & 19,1 \\
& Jawa Timur & 33 & 12,4 \\
& Kalimantan & 9 & 3,3 \\
& Nusa Tenggara Barat & 1 & 0,3 \\
& Papua & 1 & 0,3 \\
& Sulawesi & 10 & 3,7 \\
& Sumatera & 45 & 16,9 \\
& Yogyakarta & 52 & 19,5 \\
\hline \multirow{5}{*}{ Rekan Perjalanan } & Sendiri & 9 & 3,3 \\
& Istri/Suami & 13 & 4,8 \\
& Teman & 214 & 80,1 \\
& Keluarga & 30 & 11,2 \\
& Tour \& Travel & 1 & 0,3 \\
\hline \multirow{5}{*}{ Jumlah Kunjungan } & Pertama kali & 74 & 27,7 \\
& Kedua kali & 30 & 11,2 \\
& Ketiga kali & 26 & 9,7 \\
& Z Empat kali & 137 & 51,3 \\
\hline
\end{tabular}

Berdasarkan seluruh data responden terkait karakteristik pengunjung di Warung Kopi Klotok Pakem Yogyakarta, 51\% pengunjung yang berjenis kelamin lakilaki lebih banyak dibandingkan dengan perempuan, dengan rentang usia 18 - 25 tahun. Kategori rentang umur tersebut sesuai dengan pendidikan terakhir pengunjung yang mayoritas berada pada pendidikan SMA dan S1. Selanjutnya, pengunjung terbanyak di Warung Kopi Klotok berasal dari pulau Jawa khususnya yang berasal dari Yogyakarta. Mayoritas responden pada penelitian ini mengunjungi Warung Kopi Klotok Pakem Yogyakarta bersama temannya dan lebih dari setengah populasi penelitian ini telah lebih dari empat kali berkunjung ke Warung Kopi Klotok Pakem Yogyakarta. 
Tingkat Persetujuan Memorable Culinary Tourism Experiences di Warung Kopi Klotok

Selanjutnya akan dipaparkan tingkat persetujuan wisatawan terhadap memorable culinary tourism experience (MCTE) di Warung Kopi Klotok. Seperti dipaparkan sebelumnya, penelitian ini menggunakan lima dimensi MCTE, yang terdiri dari Budaya Lokal (Local Culture), Dekorasi (Décor), Kualitas Pelayanan (Service Quality), Interaksi Sosial (Social Interaction) dan Kebaruan (Novelty). Selain itu, bagian ini juga akan dipaparkan tingkat persetujuan wisatawan terhadap keinginan untuk berkunjung kembali.

Tabel 3. Tingkat Persetujuan Memorable Culinary Tourism Experiences di Waurng Kopi Klotok Pakem Yogyakarta

\begin{tabular}{|c|c|c|c|}
\hline Dimensi & Pernyataan & Total Skor & Keterangan \\
\hline \multirow{5}{*}{$\begin{array}{l}\text { Budaya } \\
\text { Lokal }\end{array}$} & $\begin{array}{l}\text { Saya merasa resep makanan yang ada } \\
\text { di hidangan Warung Kopi Klothok } \\
\text { Pakem telah menggunakan resep } \\
\text { lokal khas budaya jawa }\end{array}$ & 904 & Sangat Tinggi \\
\hline & $\begin{array}{l}\text { Saya merasa telah mendapatkan } \\
\text { kesempatan untuk merasakan } \\
\text { hidangan yang dimasak dengan } \\
\text { teknik khusus khas budaya jawa }\end{array}$ & 852 & Tinggi \\
\hline & $\begin{array}{l}\text { Saya memperoleh kesempatan untuk } \\
\text { merasakan sajian cita rasa makanan } \\
\text { khas budaya jawa }\end{array}$ & 883 & Tinggi \\
\hline & $\begin{array}{l}\text { Saya telah merasakan budaya lokal } \\
\text { dengan cara mengonsumsi hidangan } \\
\text { di Warung Kopi Klotok Pakem }\end{array}$ & 873 & Tinggi \\
\hline & $\begin{array}{l}\text { Saya merasa bahwa Warung Kopi } \\
\text { Klotok } \quad \text { Pakem dapat } \\
\text { merepresentasikan budaya jawa }\end{array}$ & 920 & Sangat Tinggi \\
\hline \multicolumn{2}{|c|}{ Nilai Rata-rata } & 886,4 & Sangat Tinggi \\
\hline
\end{tabular}




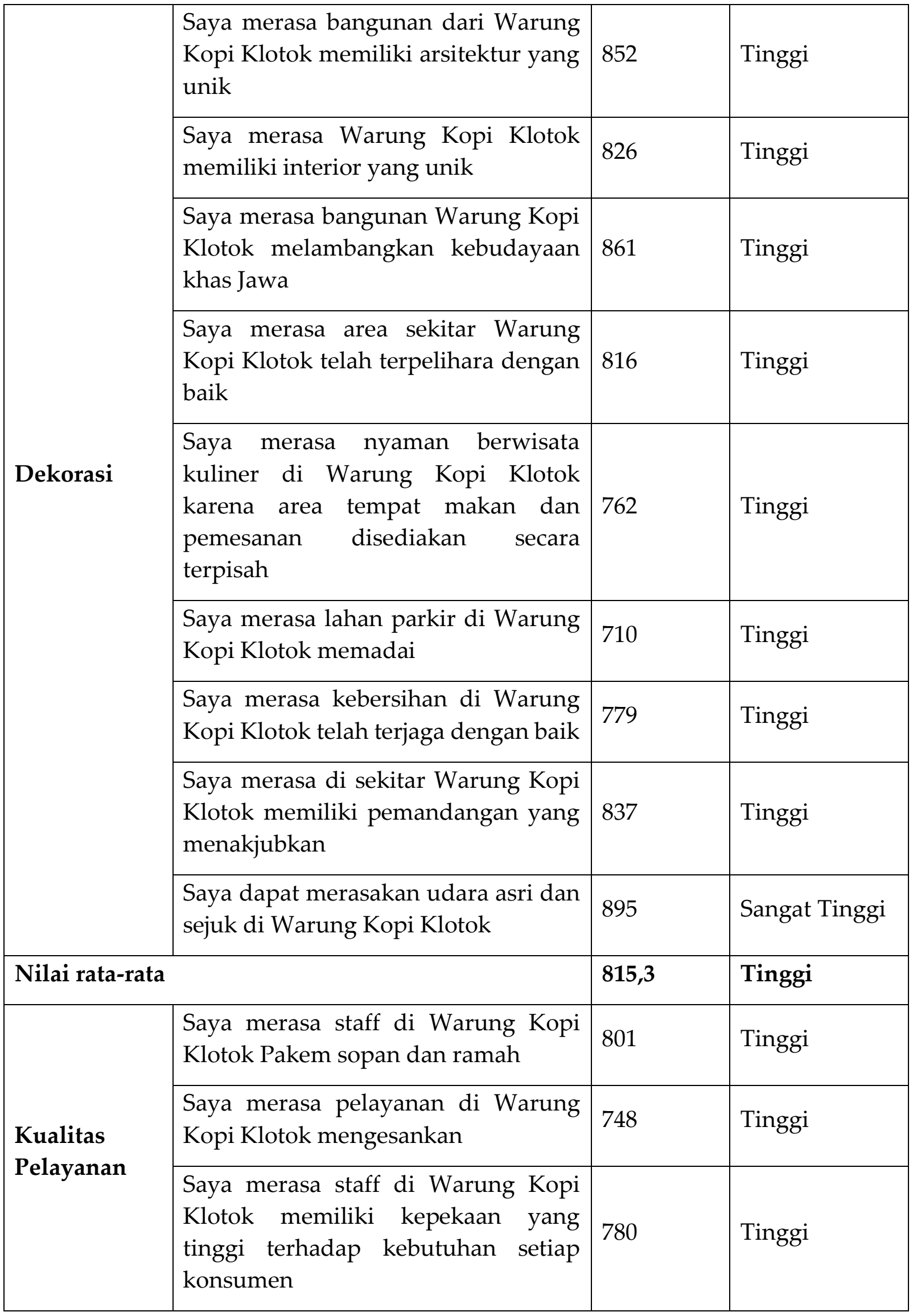




\begin{tabular}{|c|c|c|c|}
\hline \multicolumn{2}{|l|}{ Nilai rata-rata } & 776,3 & Tinggi \\
\hline \multirow{4}{*}{$\begin{array}{l}\text { Interaksi } \\
\text { Sosial }\end{array}$} & $\begin{array}{l}\text { Saya merasa Warung Kopi Klotok } \\
\text { menjadi tempat yang nyaman untuk } \\
\text { berkumpul dan berbagi cerita } \\
\text { bersama rekan perjalanan/keluarga } \\
\text { dan atau wisatawan lain }\end{array}$ & 871 & Sangat Tinggi \\
\hline & $\begin{array}{l}\text { Saya merasa dengan berkunjung ke } \\
\text { Warung Kopi Klotok dapat } \\
\text { mempererat hubungan saya dengan } \\
\text { rekan perjalanan/keluarga }\end{array}$ & 853 & Tinggi \\
\hline & $\begin{array}{l}\text { Saya merasa Warung Kopi Klotok } \\
\text { merupakan destinasi yang tepat } \\
\text { untuk berinteraksi dengan orang baru }\end{array}$ & 749 & Tinggi \\
\hline & $\begin{array}{l}\text { Saya merasa penting untuk mengajak } \\
\text { rekan perjalanan/keluarga saat } \\
\text { berkunjung ke Warung Kopi Klotok }\end{array}$ & 839 & Tinggi \\
\hline \multicolumn{2}{|l|}{ Nilai rata-rata } & 828 & Tinggi \\
\hline \multirow{2}{*}{ Kebaruan } & $\begin{array}{l}\text { Mengunjungi Warung Kopi Klotok } \\
\text { merupakan pengalaman yang baru } \\
\text { bagi saya }\end{array}$ & 724 & Tinggi \\
\hline & $\begin{array}{l}\text { Mencicipi sajian di Warung Kopi } \\
\text { Klotok merupakan pengalaman yang } \\
\text { baru bagi saya }\end{array}$ & 695 & Tinggi \\
\hline \multicolumn{2}{|l|}{ Nilai rata-rata } & 795 & Tinggi \\
\hline \multirow{3}{*}{$\begin{array}{l}\text { Minat } \\
\text { Berkunjung } \\
\text { Kembali }\end{array}$} & $\begin{array}{l}\text { Setelah kunjungan ini, saya memiliki } \\
\text { keinginan / minat untuk berkunjung } \\
\text { kembali lagi ke Warung Kopi Klotok } \\
\text { di masa yang akan datang }\end{array}$ & 842 & Tinggi \\
\hline & $\begin{array}{l}\text { Warung Kopi Klotok akan kembali } \\
\text { menjadi destinasi wisata kuliner saat } \\
\text { mengunjungi Yogyakarta }\end{array}$ & 844 & Tinggi \\
\hline & $\begin{array}{l}\text { Setelah kunjungan ini, saya akan } \\
\text { merekomendasikan kepada teman / }\end{array}$ & 857 & Tinggi \\
\hline
\end{tabular}




\begin{tabular}{|l|l|l|l|}
\hline & $\begin{array}{l}\text { keluarga / rekan untuk mengunjungi } \\
\text { Warung Kopi Klotok }\end{array}$ & $\begin{array}{l}\text { Setelah kunjungan ini, saya akan } \\
\text { menceritakan hal-hal yang bagus / } \\
\text { positif tentang Warung }\end{array}$ & 841 \\
\hline Nilai rata-rata & $\mathbf{8 4 6}$ & Tinggi \\
\hline
\end{tabular}

Tabel di atas menunjukkan tingkat persetujuan wisatawan terhadap variabel MCTE di Warung Kopi Klotok. Yang menarik dari temuan penelitian ini adalah bahwa Budaya Lokal merupakan dimensi dengan tingkat persetujuan paling tinggi menurut wisatawan dengan total skor sebesar 886,4; kemudian diikuti dengan keempat dimensi lainnya yang mendapat tingkat persetujuan "tinggi", yaitu dimensi Interaksi Sosial dengan total skor sebesar 828; dimensi Dekorasi dengan total skor sebesar 815,3; dimensi kualitas pelayanan dengan total skor sebesar 776,3; dan dimensi kebaruan dengan total skor sebesar 709,5. Selain itu, minat berkunjung kembali dari wisatawan juga mendapat tingkat persetujuan yang tinggi, yaitu sebesar 846 .

\section{Hubungan Memorable Culinary Tourism Experiences terhadap Minat Berkunjung}

\section{Kembali di Warung Kopi Klotok Pakem Yogyakarta}

Selanjutnya akan dipaparkan hubungan antara variabel Memorable Culinariy tourism experience dengan minat berkunjung kembali wisatawan ke Warung Kopi Klotok. Hasil analisis akan dipaparkan melalui table korelasi.

\section{Hubungan Budaya Lokal terhadap Minat Berkunjung Kembali}

Pada bagian selanjutnya akan dipaparkan mengenai hubungan antara budaya local dan minat berkunjung kembali. 
Tabel 4. Output Uji Korelasi Spearman Dimensi Budaya Lokal terhadap Minat Berkunjung Kembali

\begin{tabular}{|c|c|c|c|c|}
\hline \multicolumn{5}{|l|}{ Correlations } \\
\hline & & & SumLC & SumRev \\
\hline \multirow[t]{6}{*}{ Spearman's rho } & \multirow[t]{3}{*}{$\begin{array}{l}\text { Sum } \\
\text { LC }\end{array}$} & Correlation Coefficient & 1 & $.407^{* *}$ \\
\hline & & $\begin{array}{l}\text { Sig. } \\
\text { (2-tailed) }\end{array}$ & . & 0 \\
\hline & & $\mathrm{N}$ & 267 & 267 \\
\hline & \multirow[t]{3}{*}{ SumRev } & Correlation Coefficient & $.407^{* *}$ & 1 \\
\hline & & $\begin{array}{l}\text { Sig. } \\
\text { (2-tailed) }\end{array}$ & 0 & . \\
\hline & & $\mathrm{N}$ & 267 & 267 \\
\hline
\end{tabular}

Berdasarkan output Tabel 4 di atas diketahui bahwa hasil analisis menggunakan uji korelasi Spearman menunjukkan angka koefisien korelasi sebesar 0,407. Tingkat kekuatan hubungan (korelasi) antara dimensi budaya lokal terhadap minat berkunjung kembali ke Warung Kopi Klotok Pakem Yogyakarta sebesar 0,407 tersebut termasuk ke dalam kategori hubungan yang sedang (dilihat dari tabel interpretasi koefisien korelasi dalam De Vaus,2002:259). Selain itu, angka koefisien yang didapatkan dari hasil uji korelasi Spearman dalam tabel di atas bernilai positif sehingga hubungan dari dimensi budaya lokal terhadap minat berkunjung kembali ke Warung Kopi Klotok Pakem Yogyakarta bersifat searah atau memiliki jenis hubungan yang searah. Sifat hubungan yang bernilai positif dari dimensi budaya lokal terhadap minat berkunjung kembali tersebut dapat diartikan bahwa apabila MCTEs yang berkaitan dengan dimensi budaya lokal yang diperoleh pengunjung di 
Warung Kopi Klotok Pakem Yogyakarta dapat ditingkatkan maka minat pengunjung untuk berkunjung kembali juga akan meningkat.

Selain nilai koefisien korelasi, nilai signifikansi juga digunakan untuk menguji ada atau tidaknya hubungan antara dimensi budaya lokal terhadap minat berkunjung kembali ke Warung Kopi Klotok Pakem Yogyakarta. Jika dilihat dari nilai signifikansi atau Sig. (2-tailed) berdasarkan output tabel di atas maka nilainya adalah 0. Apabila nilai Sig. (2-tailed) $\leq$ 0,05 maka Ho ditolak. Dengan demikian, nilai signifikansi bernilai 0 dalam dimensi ini dapat diartikan bahwa ada hubungan antara dimensi budaya lokal terhadap minat berkunjung kembali.

\section{Hubungan Dekorasi terhadap Minat Berkunjung Kembali}

Tabel 5. Output Uji Korelasi Spearman Dimensi Dekorasi terhadap Minat Berkunjung Kembali

\begin{tabular}{|l|l|l|l|l|}
\hline \multicolumn{2}{|l|}{ Correlations } & \multicolumn{2}{l|}{ SumD } & SumRev \\
\hline \multirow{2}{*}{ Spearman's rho } & \multirow{2}{*}{ SumD } & Correlation Coefficient & 1 & $.541^{* *}$ \\
\cline { 3 - 6 } & $\begin{array}{l}\text { Sig. } \\
\text { (2-tailed) }\end{array}$ &. & 0 \\
\cline { 3 - 6 } & N & 267 & 267 \\
\cline { 3 - 6 } & \multirow{2}{*}{ SumRev } & Correlation Coefficient & $.541^{* *}$ & 1 \\
\cline { 3 - 6 } & $\begin{array}{l}\text { Sig. } \\
\text { (2-tailed) }\end{array}$ & 0 &. \\
\cline { 3 - 5 } & N & 267 & 267 \\
\hline
\end{tabular}


Berdasarkan output Tabel 5 di atas dapat diketahui bahwa hasil analisis menggunakan uji korelasi Spearman menunjukkan angka koefisien korelasi sebesar 0,541. Tingkat kekuatan hubungan (korelasi) antara dimensi dekorasi terhadap minat berkunjung kembali ke Warung Kopi Klotok Pakem Yogyakarta sebesar 0,541 tersebut termasuk ke dalam kategori hubungan yang kuat (dilihat dari tabel interpretasi koefisien korelasi dalam De Vaus,2002:259). Selain itu, angka koefisien yang didapatkan dari hasil uji korelasi Spearman dari tabel di atas bernilai positif sehingga hubungan dari dimensi dekorasi terhadap minat berkunjung kembali ke Warung Kopi Klotok Pakem Yogyakarta bersifat searah atau memiliki jenis hubungan yang searah. Sifat hubungan dari dimensi dekorasi terhadap minat berkunjung kembali tersebut berarti bahwa apabila MCTEs yang berhubungan dengan dimensi dekorasi yang diperoleh pengunjung di Warung Kopi Klotok Pakem Yogyakarta dapat ditingkatkan maka minat pengunjung untuk berkunjung kembali juga akan meningkat.

Selain nilai koefisien korelasi, nilai signifikansi digunakan untuk menguji ada atau tidaknya hubungan antara dimensi dekorasi terhadap minat berkunjung kembali ke Warung Kopi Klotok Pakem Yogyakarta. Jika dilihat dari nilai signifikansi atau Sig. (2-tailed) berdasarkan output tabel di atas maka nilainya adalah 0. Apabila nilai Sig. (2tailed $\leq$ 0,05 maka $\mathrm{H}_{0}$ ditolak. Dengan demikian, nilai signifikansi bernilai 0 pada dimensi ini dapat diartikan bahwa ada hubungan antara dimensi dekorasi terhadap minat berkunjung kembali. 


\section{Hubungan Kualitas Pelayanan terhadap Minat Berkunjung Kembali}

Tabel 6. Output Uji Korelasi Spearman Dimensi Kualitas Pelayanan terhadap Minat Berkunjung Kembali

\begin{tabular}{|l|l|l|l|l|}
\hline \multicolumn{2}{|l|}{ Correlations } & \multicolumn{2}{|l|}{ SumSQ } & SumRev \\
\hline Spearman's rho & SumSQ & Correlation Coefficient & 1 & $.456^{* *}$ \\
\cline { 3 - 5 } & $\begin{array}{l}\text { Sig. } \\
(2-\text { tailed })\end{array}$ &. & 0 \\
\cline { 3 - 5 } & N & 267 & 267 \\
\cline { 3 - 5 } & \multirow{2}{|l|}{ SumRev } & Correlation Coefficient & $.456^{* *}$ & 1 \\
\cline { 3 - 5 } & $\begin{array}{l}\text { Sig. } \\
(2-\text { tailed })\end{array}$ & 0 &. \\
\cline { 3 - 5 } & N & 267 & 267 \\
\hline
\end{tabular}

Berdasarkan output Tabel 6 di atas dapat diketahui bahwa hasil analisis menggunakan uji korelasi Spearman menunjukkan angka koefisien korelasi sebesar 0,456. Tingkat kekuatan hubungan (korelasi) antara dimensi kualitas pelayanan terhadap minat berkunjung kembali ke Warung Kopi Klotok Pakem Yogyakarta sebesar 0,456 tersebut termasuk ke dalam kategori hubungan yang sedang (dilihat dari tabel interpretasi koefisien korelasi dalam De Vaus, 2002:259). Selain itu, angka koefisien yang didapatkan dari hasil uji korelasi Spearman dari tabel di atas bernilai positif sehingga hubungan dari dimensi kualitas pelayanan terhadap minat berkunjung kembali ke Warung Kopi Klotok Pakem Yogyakarta bersifat searah atau memiliki jenis hubungan yang searah. Sifat hubungan dari dimensi kualitas pelayanan terhadap minat berkunjung kembali tersebut dapat diartikan bahwa apabila MCTEs yang berkaitan dengan dimensi kualitas pelayanan yang diperoleh 
pengunjung di Warung Kopi Klotok Pakem Yogyakarta dapat ditingkatkan maka minat pengunjung untuk berkunjung kembali juga akan meningkat.

Selain nilai koefisien korelasi, nilai signifikansi pun digunakan untuk menguji ada atau tidaknya hubungan antara dimensi kualitas pelayanan terhadap minat berkunjung kembali ke Warung Kopi Klotok Pakem Yogyakarta. Jika dilihat dari nilai signifikansi atau Sig. (2-tailed) berdasarkan output tabel di atas maka nilainya adalah 0. Apabila nilai Sig. (2-tailed) $\leq 0,05$ maka $\mathrm{H}_{0}$ ditolak. Dengan demikian, nilai signifikansi bernilai 0 pada dimensi ini dapat diartikan bahwa ada hubungan antara dimensi kualitas pelayanan terhadap minat berkunjung kembali.

\section{Hubungan Interaksi Sosial terhadap Minat Berkunjung Kembali}

Tabel 7. Output Uji Korelasi Spearman Dimensi Interaksi Sosial terhadap Minat Berkunjung Kembali

\begin{tabular}{|c|c|c|c|c|}
\hline \multicolumn{5}{|l|}{ Correlations } \\
\hline & & & SumSI & SumRev \\
\hline \multirow[t]{6}{*}{ Spearman's rho } & \multirow[t]{3}{*}{ SumSI } & Correlation Coefficient & 1 & $.599^{* *}$ \\
\hline & & Sig. (2-tailed) & . & 0 \\
\hline & & $\mathrm{N}$ & 267 & 267 \\
\hline & \multirow[t]{3}{*}{ SumRev } & Correlation Coefficient & $.599^{* *}$ & 1 \\
\hline & & Sig. (2-tailed) & 0 & . \\
\hline & & $\mathrm{N}$ & 267 & 267 \\
\hline
\end{tabular}


Berdasarkan output Tabel 7 di atas dapat diketahui bahwa hasil analisis menggunakan uji korelasi Spearman menunjukkan angka koefisien korelasi sebesar 0,599. Tingkat kekuatan hubungan (korelasi) antara dimensi interaksi sosial terhadap minat berkunjung kembali di Warung Kopi Klotok Pakem Yogyakarta sebesar 0,599 tersebut termasuk ke dalam kategori hubungan yang kuat (apabila dilihat dari tabel interpretasi koefisien korelasi dalam De Vaus, 2002:259). Selain itu, angka koefisien yang didapatkan dari hasil uji korelasi Spearman dari tabel di atas bernilai positif sehingga hubungan dari dimensi interaksi sosial terhadap minat berkunjung kembali ke Warung Kopi Klotok Pakem Yogyakarta bersifat searah atau memiliki jenis hubungan yang searah. Sifat hubungan dari dimensi interaksi sosial terhadap minat berkunjung kembali tersebut dapat diartikan bahwa apabila MCTEs yang berkaitan dengan dimensi interaksi sosial yang diperoleh pengunjung di Warung Kopi Klotok Pakem Yogyakarta dapat ditingkatkan maka minat pengunjung untuk berkunjung kembali juga akan meningkat.

Selain nilai koefisien korelasi, nilai signifikansi juga digunakan untuk menguji ada atau tidaknya hubungan antara dimensi interaksi sosial terhadap minat berkunjung kembali ke Warung Kopi Klotok Pakem Yogyakarta. Jika dilihat dari nilai signifikansi atau Sig. (2-tailed) berdasarkan output tabel di atas maka nilainya adalah 0. Apabila nilai Sig. (2-tailed) $\leq 0,05$ maka $\mathrm{H}_{0}$ ditolak. Dengan demikian, nilai signifikansi bernilai 0 dalam dimensi ini menunjukkan ada hubungan antara dimensi interaksi sosial terhadap minat berkunjung kembali. 


\section{Hubungan Kebaruan terhadap Minat Berkunjung Kembali}

Tabel 8. Output Uji Korelasi Spearman Dimensi Kebaruan terhadap Minat

Berkunjung Kembali

\begin{tabular}{|c|c|c|c|c|}
\hline \multicolumn{5}{|l|}{ Correlations } \\
\hline & & & SumN & SumRev \\
\hline \multirow[t]{6}{*}{ Spearman's rho } & \multirow[t]{3}{*}{ SumN } & Correlation Coefficient & 1 & $.320^{* *}$ \\
\hline & & $\begin{array}{l}\text { Sig. } \\
\text { (2-tailed) }\end{array}$ & $\cdot$ & 0 \\
\hline & & $\mathrm{N}$ & 267 & 267 \\
\hline & \multirow[t]{3}{*}{ SumRev } & Correlation Coefficient & $.320^{* *}$ & 1 \\
\hline & & $\begin{array}{l}\text { Sig. } \\
\text { (2-tailed) }\end{array}$ & 0 & . \\
\hline & & $\mathrm{N}$ & 267 & 267 \\
\hline
\end{tabular}

Berdasarkan output Tabel 8 di atas dapat diketahui bahwa hasil analisis menggunakan uji korelasi Spearman menunjukkan angka koefisien korelasi sebesar 0,320. Tingkat kekuatan hubungan (korelasi) antara dimensi kebaruan terhadap minat berkunjung kembali ke Warung Kopi Klotok Pakem Yogyakarta sebesar 0,320 tersebut termasuk ke dalam kategori hubungan yang sedang (dilihat dari tabel interpretasi koefisien korelasi dalam De Vaus, 2002:259). Selain itu, angka koefisien yang didapatkan dari hasil uji korelasi Spearman dari tabel di atas bernilai positif sehingga hubungan dari dimensi kebaruan terhadap minat berkunjung kembali ke Warung Kopi Klotok Pakem Yogyakarta bersifat searah atau memiliki jenis hubungan yang searah. Sifat hubungan dari dimensi kebaruan terhadap minat berkunjung kembali tersebut dapat pula diartikan bahwa apabila MCTEs yang berkaitan dengan dimensi kebaruan yang diperoleh pengunjung di Warung Kopi Klotok Pakem 
Yogyakarta dapat ditingkatkan maka minat pengunjung untuk berkunjung kembali juga akan meningkat.

Selain nilai koefisien korelasi, nilai signifikansi juga digunakan untuk menguji ada atau tidaknya hubungan antara dimensi kebaruan terhadap minat berkunjung kembali ke Warung Kopi Klotok Pakem Yogyakarta. Jika dilihat dari nilai signifikansi atau Sig. (2-tailed) berdasarkan output tabel di atas maka nilainya adalah 0. Apabila nilai Sig. (2-tailed) $\leq$ 0,05 maka Ho ditolak. Dengan demikian, nilai signifikansi bernilai 0 pada dimensi ini menunjukkan adanya hubungan antara dimensi kebaruan terhadap minat berkunjung kembali.

\section{Kesimpulan dan Saran}

\section{Kesimpulan}

Penelitian ini membahas mengenai hubungan Memorable Culinay Tourism Experience (MCTE) terhadap minat berkunjung kembali ke Warung Kopi Klotok Pakem Yogyakarta dengan penyebaran kuesioner sebanyak 267 responden kepada pengunjung. Berdasarkan seluruh data responden terkait karakteristik pengunjung di Warung Kopi Klotok Pakem Yogyakarta yang telah dijabarkan sebelumnya, mayoritas pengunjung adalah laki-laki dan merupakan pelajar mahasiswa, dengan rentang usia 18 - 25 tahun. Kategori rentang umur tersebut sesuai dengan pendidikan terakhir pengunjung yang mayoritas berada pada pendidikan SMA dan S1. Selanjutnya, pengunjung terbanyak berasal dari pulau Jawa khususnya yang berasal dari Yogyakarta. Mayoritas responden pada penelitian ini mengunjungi Warung Kopi Klotok Pakem Yogyakarta bersama temannya dan mayoritas dari mereka telah lebih dari empat kali berkunjung ke Warung Kopi Klotok Pakem Yogyakarta. 
Berdasarkan hasil analisis statistik deskriptif dari masing-masing variabel, kesimpulan mengenai tingkat persetujuan responden terhadap masing-masing dimensi dari MCTE berada pada kategori tinggi hingga sangat tinggi. Adapun variabel minat berkunjung kembali berada di rentang kategori tingkat persetujuan tinggi. Dimensi budaya lokal berada di rentang kategori tingkat persetujuan sangat tinggi, sedangkan empat dimensi lainnya berada di rentang kategori tingkat persetujuan tinggi.

Hasil uji korelasi dimensi budaya lokal terhadap minat berkunjung kembali menunjukkan kekuatan hubungan (korelasi) yang sedang dengan angka koefisien korelasi sebesar 0,407. Hasil uji korelasi dimensi dekorasi terhadap minat berkunjung kembali menunjukkan kekuatan hubungan (korelasi) yang kuat dengan angka koefisien korelasi sebesar 0,541. Sementara itu, hasil uji korelasi dimensi kualitas pelayanan terhadap minat berkunjung kembali menunjukkan kekuatan hubungan (korelasi) yang sedang dengan angka koefisien korelasi sebesar 0,456. Hasil uji korelasi dimensi interaksi sosial terhadap minat berkunjung kembali menunjukkan kekuatan hubungan (korelasi) yang kuat dengan angka koefisien korelasi sebesar 0,599. Adapun nilai signifikansi dalam dimensi ini ialah 0. Dengan demikian, jika ditinjau dari hipotesis penelitian maka ada hubungan antara dimensi interaksi sosial terhadap minat berkunjung kembali. Hasil uji korelasi dimensi kebaruan terhadap minat berkunjung kembali menunjukkan kekuatan hubungan (korelasi) yang sedang dengan angka koefisien korelasi sebesar 0,320.

Penelitian ini bukan hanya telah membuktikan bahwa variable Memorable Tourism Cullinary Experience yang diadopsi dari konsep Memorable Tourism Experience dapat diaplikasikan dengan baik pada penelitian mengenai pegalaman wisatawan dalam menikmati kuliner tradisional, namun demikian juga dapat menunjukkan variable mana yang mendapat tingkat persetujuan paling tinggi menurut wisatawan. 
Selain itu, penelitian ini juga telah menunjukkan variabel mana yang memiliki korelasi paling kuat dengan minat kunjungan kembali. Untuk selanjutnya, hasil penelitian ini dapat dijadikan rekomendasi praktis bagi para pegiat pariwisata kuliner mengenai aspek-aspek yang perlu ditekankan dalam mengembangkan wisata kuliner tradisional.

\section{Saran Penelitian Selanjutnya}

Berdasarkan pembahasan yang telah dijelaskan sebelumnya, terdapat beberapa saran dalam penelitian ini yang dapat dipertimbangkan bagi penelitian selanjutnya. Saran dalam penelitian ini adalah sebagai berikut:

- Sampel dalam penelitian ini berfokus pada seluruh pengunjung. Diharapkan bahwa pada penelitian selanjutnya mengkaji dari sisi wisatawan.

- Pada dasarnya, MCTE merupakan adaptasi dari MTE pada wisata kuliner sehingga indikatornya pun masih dapat berubah sesuai dengan lokasi penelitian. Berdasarkan hal tersebut, diharapkan bahwa penelitian selanjutnya dapat mengembangkan indikator yang sesuai dengan lokasi penelitian.

- Jika penelitian selanjutnya juga akan menggunakan konsep MCTEs maka diharapkan dapat mengeksplorasi tempat wisata berbasis kuliner lainnya.

- Penelitian ini merupakan penelitian kuantitatif. Berdasarkan hal tersebut, ada baiknya perlu untuk diadakan penelitian secara kualitatif untuk membahas hubungan MCTEs terhadap minat kunjungan kembali secara lebih mendalam.

\section{Daftar Pustaka}

Ageevaa, E., \& Foroudi, P. (2019). Tourists' destination image through regional tourism: From supply and demand sides perspectives. Journal of Business Research, 101, 334-348. 
Altinay, L., Paraskevas, A., \& Jang, S. S. (2008). Planning research in hospitality and tourism. UK : Elsevier Ltd.

Bhuiyan, M. M. M., \& Iqrar, M. (2019). How ethnic restaurants' product and service quality effects customer satisfaction: A study on Indian sub-continental restaurants in Lappeenranta.

Baltescu, C. A. (2016). Culinary experiences as a key tourism attraction. Case Study: Brasov County. Bulletin of the Transilvania University of Brasov. Economic Sciences. Series V, 9(2), 107-112.

Chandralal, L., \& Valenzuela, F. R. (2013). Exploring memorable tourism experiences: Antecedents and behavioural outcomes. Journal of Economics, Business and Management, 1(2), 177-181.

Chandralal, L., \& Valenzuela, F. R. (2015). Memorable tourism experiences: Scale development. Contemporary Management Research, 11(3).

Chandralal, L., Rindfleish, J., \& Valenzuela, F. (2014). An application of travel blog narratives to explore memorable tourism experiences. Asia Pacific Journal of Tourism Research, 20(6), 680-693.

Coelho, Mariana de Freitas., de Sevilha Gosling, M., \& de Almeida, A. S. A. (2018). Tourism experiences: Core processes of memorable trips. Journal of Hospitality and Tourism Management, 37, 11-22.

De Vaus, D., \& de Vaus, D. (2013). Surveys in social research. Routledge.

Devian, Paskalis. 2018. "Integrasi Service Performance dan Model KANO untuk Evaluasi Kinerja Layanan pada Warung Kopi Klotok Yogyakarta". Skripsi. Yogyakarta: Universitas Gadjah Mada.

Fernandez, Tessa, \& Cruz, Mariana. (2016). Dimensions and outcomes of experience quality in tourism: The case of Port wine cellars. Journal of Retailing and Consumer Services, 31, 371-379.

Gerdt, S.-O., Wagner, E., \& Schewe, G. (2019). The relationship between sustainability and customer satisfaction in hospitality: An explorative investigation using eWOM as a data source. Tourism Management, 74, 155-172.

Hall, C. M., \& Sharples, L. (2003). The consumption of experiences or the experience of consumption? An introduction to the tourism of taste. In Food tourism around the world. Routledge.

Hallak, R., Assaker, G., \& El-Haddad, R. (2018). Re-examining the relationships among perceived quality, value, satisfaction, and destination loyalty: A higherorder structural model. Journal of Vacation Marketing, 24(2), 118-135. 
Hjalager, A. M., \& Richards, G. (Eds.). (2002). Tourism and gastronomy (Vol. 11). Routledge.

Huang, Songshan Sam, \& Hsu, Cathy H. (2009). Effects of travel motivation, past experience, perceived constraint, and attitude on revisit intention. Journal of travel research, 48(1), 29-44.

Kim, Jong-Hyeong. (2010). Determining the factors affecting the memorable nature of travel experiences. Journal of Travel $\mathcal{E}$ Tourism Marketing, 27(8), 780-796.

Kim, Jong-Hyeong. (2014). The antecedents of memorable tourism experiences: The development of a scale to measure the destination attributes associated with memorable experiences. Tourism management, 44, 34-45.

Kim, Jong-Hyeong., Ritchie, J. B., \& McCormick, B. (2010). Development of a scale to measure memorable tourism experiences. Journal of Travel Research, 51(1), 1225.

Kim, Kyungmi, Hallab, Zaher, \& Kim, J. N. (2012). The moderating effect of travel experience in a destination on the relationship between the destination image and the intention to revisit. Journal of Hospitality Marketing $\mathcal{E}$ Management, 21(5), 486-505.

Lee, D.S., \& Han, H.S. (2016). A study on the behavior intention of festival visitors by using theory of planned behavior: Focusing on moderation effect of perceived risk. Tourism Research, 41, 205-225.

Lin, Cung-Hsien. (2012). Effects of cuisine experience, psychological well-being, and self-health perception on the revisit intention of hot springs tourists. Journal of Hospitality E Tourism Research, 38(2), 243-265.

Lin, Lin, \& Mao, Pei-Chuan. (2015). Food for memories and culture-A content analysis study of food specialties and souvenirs. Journal of Hospitality and Tourism Management, 22, 19-29.

Mahdzar, M., Shuib, A., Ramachandran, S., \& Afandi, S. H. M. (2015). The role of destination attributes and memorable tourism experience in understanding tourist revisit intentions. American-Eurasian Journal of Agricultural $\mathcal{E}$ Environmental Sciences (Tourism \& Environment, Social and Management Sciences), 15, 32-39.

Papadimitriou, D., Kaplanidou, K., \& Apostolopoulou, A. (2018). Destination image components and word-of-mouth intentions in urban tourism: A multigroup approach. Journal of Hospitality and Tourism Research, 42, 503-527. 
Park, E., Kim, S., \& Yeoman, I. (2019). Eating in Asia: Understanding Food Tourism and Its Perspectives in Asia. In Food Tourism in Asia (pp. 3-27). Springer, Singapore.

Peter, Björk \& Kauppinen-Räisänen, H. (2014). Culinary-gastronomic tourism-a search for local food experiences. Nutrition $\mathcal{E}$ Food Science.

Rao, Purba Halady. (2008). Predictive modelling in strategic marketing. PHI Learning Pvt. Ltd.

Singh, Rashmi., \& Singh, Janmejay. (2019). Destination Attributes to Measure Tourist Revisit Intention: A Scale Development. Global Business Review, 20(2), 549-572.

Smith, Sylvia, \& Costello, Carol. (2008). Culinary tourism: Satisfaction with a culinary event utilizing importance-performance grid analysis. Journal of Vacation Marketing, 15(2), 99-110.

Stone, Matther J., Soulard, Joelle, Migacz, S., \& Wolf, E. (2017). Elements of memorable food, drink, and culinary tourism experiences. Journal of Travel Research, 57(8), 1121-1132.

Tan, W. K., \& Wu, C. E. (2016). An investigation of the relationships among destination familiarity, destination image and future visit intention. Journal of Destination Marketing \& Management, 5(3), 214-226.

Tsai, C.F. (2015). The Relationships among Destination Image, Perceived Quality, Emotional Place Attachment, Tourist Satisfaction, and Post-visiting Behavior Intentions. Marketing Review, 12, 455-479.

Umar, H. (1998). Riset Sumber Daya Manusia, PT. Gramedia Pustaka Utama, Jakarta.

Yusuf, M. (2017). Measuring Tourist's Motivations for Consuming Local Angkringan Street Food in Yogyakarta, Indonesia. Journal of Indonesian Tourism and Development Studies, 5(2), 65-72.

Zhang, H., Wu, Y., \& Buhalis, D. (2018). A model of perceived image, memorable tourism experiences and revisit intention. Journal of destination marketing $\mathcal{E}$ management, 8, 326-336. 


\section{Profil Penulis}

Intan Widyaningrum Puji Rahayu, S.Par adalah alumni Program Studi S 1 Pariwisata Universitas Gadjah Mada. Penulis memiliki ketertarikan pada topik penelitian pariwisata, khususnya yang berkaitan dengan wisata kuliner dengan menggunakan pendekatan kuantitatif.

Dr. Mohamad Yusuf, M.A. adalah staf pengajar pada Program Studi Pariwisata Universitas Gadjah Mada dan merupakan Tim Ahli pada Pusat Studi Pariwisata Universitas Gadjah Mada. Penulis banyak menghasilkan karya tulis dalam bidang pariwisata, dan diterbitkan pada beberapa jurnal internasional bereputasi. 